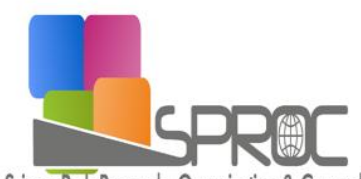

SciencePark Research, Organization \& Counseling

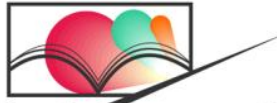

Global Journal

of Foreign Language Teaching

www.gjflt.eu

\title{
The effect of drama in the teaching of listening skills
}

Fatih Yavuz

Suggested Citation:

Teaching. 7

Global Journal of Foreign Language

Abstract

Fatih Yavuz, 
1. Introduction

Pronunciation is a kind of language activity during which anxiety is high, depending on students'

different results. Tergujeff's (2012) research shows that although teachers have different ways of 
2. Purpose of the Study

Macbeth and analysing different samples from Shakespeare's works, this study aimed to help

3. Drama Supported Procedure: What We Have Done

alphabet analysis and introduction to Shakespeare's work, Macbeth. The students watched the movie, 


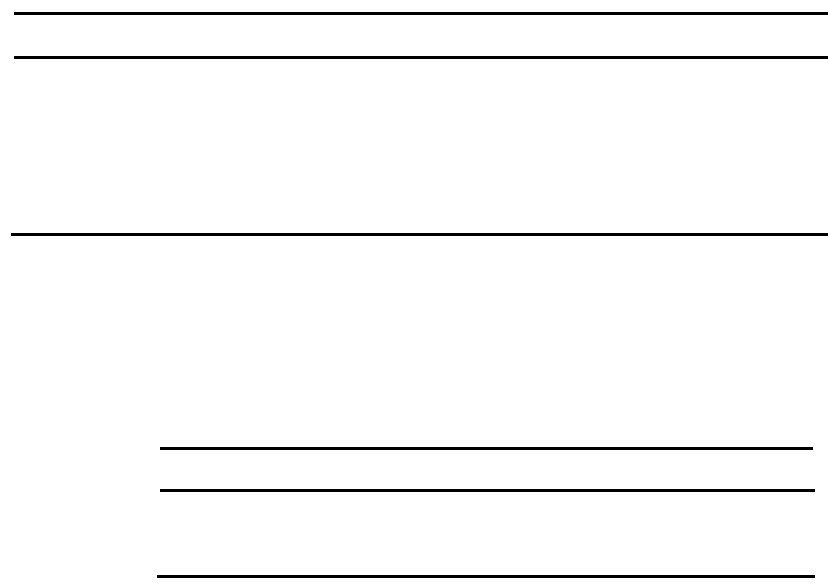

\section{Conclusion}




\section{References}

Towards a history of teaching, learning and assessment in phonetics

The 'IPA exam' - certificate of proficiency in the phonetics of phonetics teaching and learning conference

The reduction of speaking anxiety in EFL learners through drama techniques

Research in Language, 11

RELC Journal, 44

behavioral sciences

Vocal clarity through drama strategy. Procedia - social and 